\title{
POTENCIALIDADES DA ANÁLISE HISTÓRICA NOS ESTUDOS ORGANIZACIONAIS BRASILEIROS
}

POTENTIALS OF HISTORICAL ANALYSIS IN BRAZILIAN ORGANIZATION STUDIES

POTENCIALIDADES DEL ANÁLISIS HISTÓRICO EN LOS ESTUDIOS ORGANIZACIONALES BRASILEÑOS

\begin{abstract}
RESUMO
Nos últimos anos, tem sido aguda a necessidade de se constituir pesquisa organizacional voltada para as especificidades locais. Isso também ocorre no caso brasileiro, onde se observa a distância entre o contexto nacional e o dos países de onde se importam as tecnologias gerenciais aqui aplicadas. Uma das formas de se verificarem as peculiaridades da gestão e organização brasileiras é por meio da análise histórica desses modelos. Assim, este texto trata de aspectos epistemológicos e metodológicos que permitem visualizar os limites e possibilidades da pesquisa histórica no campo de Estudos Organizacionais, dando certa ênfase àqueles empreendidos no Brasil. Construímos nossa análise em três seções: a primeira trata dos pressupostos que circundam a aproximação entre a perspectiva histórica e as ciências sociais; a segunda aborda questões historiográficas diretamente relacionadas ao campo de Estudos Organizacionais; e a terceira trata de algumas contribuições da historiografia brasileira aos Estudos Organizacionais. Por fim, apresentamos alguns temas para uma agenda de pesquisa.
\end{abstract}

PALAVRAS-CHAVE Funcionalismo, história, universalismo, contexto brasileiro, historiografia.

Fábio Vizeu Ferreira vizeu@up.edu.br

Professor do Programa de Mestrado e Doutorado em Administração, Universidade Positivo - Curitiba - PR, Brasil

Recebido em 04.05.2008. Aprovado em 21.12.2009

Avaliado pelo sistema double blind review. Editor Científico: Felipe Zambaldi

\begin{abstract}
Over the last few years there has been an acute need for constituting organizational research that is directed at local specificities. This also happens in the case of Brazil, where there is seen to be a distance between the national context and that of the countries from which the management technology that is applied here is imported. One of the ways of checking the particular aspects of Brazilian management and organization is by the historical analysis of these models. This text, therefore, deals with the epistemological and methodological aspects that allow us to observe the limits and possibilities of historical research in the field of Organizational Studies, with a particular emphasis on those undertaken in Brazil. Our analysis has been constructed in three sections; the first deals with the assumptions that surround the approximation between the historical perspective and the social sciences; the second deals with historiographic issues that are directly related to the field of Organizational Studies; and the third deals with some of the contributions that Brazilian historiography have made to Organizational Studies. Finally, we present some of the themes for a research agenda.
\end{abstract}

KEYWORDS Functionalism, history, universalism, Brazilian context, historiography.

RESUMEN En los últimos años, se ha acentuado la necesidad de constituir una investigación organizacional concentrada en especificidades locales Eso también ocurre en el caso brasileño, donde se observa la distancia entre el contexto nacional y el de los países desde donde se importan las tecnologías gerenciales aquí aplicadas. Una de las formas de verificar las peculiaridades de la gestión y organización brasileñas es a través del análisis histórico de esos modelos. Así, este artículo trata de aspectos epistemológicos y metodológicos que permiten visualizar los límites y posibilidades de la investigación histórica en el campo de los Estudios Organizacionales, dando cierto énfasis a aquellos emprendidos en Brasil. Construimos nuestro análisis en tres secciones: la primera trata de los presupuestos que circundan la aproximación entre la perspectiva histórica y las ciencias sociales; la segunda aborda cuestiones historiográficas directamente relacionadas al campo de Estudios Organizacionales; y la tercera trata de algunas contribuciones de la historiografía brasileña a los Estudios Organizacionales. Finalmente, presentamos algunos temas para una agenda de investigación.

PALAVRAS CLAVE Funcionalismo; historia; universalismo; contexto brasileño; historiografía. 


\section{INTRODUÇÃO}

Em nenhum outro momento, a comunidade acadêmica se mobilizou tanto para a organização de fóruns e congressos visando o entendimento de práticas de gestão regionalmente situadas. Sejm em congressos temáticos ou chamadas especiais de revistas acadêmicas, o interesse pela prática de gestão local surge como algo importante para a comunidade internacional, mesmo para os acadêmicos residentes nos Estados Unidos, o país pivô na formação do pensamento administrativo moderno, que eram acostumados a reconhecer sua economia e o conhecimento nela fundamentado como algo universal e transferível ao resto do mundo. Um interessante exemplo desse esforço são as divisões latina, europeia e asiática da Academy of Management, a mais importante associação acadêmica norte-americana.

Uma das possíveis explicações para esses esforços é o maior comprometimento do meio acadêmico com a contextualização cultural no entendimento dos fenômenos organizacionais. De fato, as pesquisas têm demonstrado que as práticas de gestão e teorias organizacionais devem ser situadas cultural e historicamente para ser realmente significativas (KIESER, 1994; CLARK e ROWLINSON, 2004; BOOTH e ROWLINSON, 2006). No caso brasileiro, os pesquisadores têm se deparado com o desafio de entender a singularidade das práticas organizacionais deste país, um contexto significativamente diverso daquele onde se constitui a grande maioria das tecnologias de gestão que são correntemente incorporadas em todo o mundo (CALDAS e WOOD JR, 1999). Diante dessa necessidade, uma das formas de verificar os aspectos peculiares da gestão e formas de organização do Brasil é por meio do escrutínio da trajetória histórica desses modelos e das referências sociais, econômicas e políticas que os sustentaram.

Assim, pretendemos neste trabalho contribuir para o uso da perspectiva histórica na construção do conhecimento sobre a gestão e a organização brasileiras. Isso pode ocorrer mediante a adoção de um quadro teórico-conceitual constituído a partir da análise histórica (BOOTH e ROWLINSON, 2006), ou mesmo pela aplicação da pesquisa histórica enquanto método de análise empírica e analítica. Sustentamos com esse propósito que a pesquisa histórica em si mesma possibilita a teorização sobre os fenômenos organizacionais contemporâneos, justamente por permitir um melhor entendimento sobre problemas, temas priorizados e aspectos gerais relacionados à prática organizacional (KIESER, 1994; BEDEIAN, 2004). Nesse sentido, Jacques (2006) e Bedeian (2004) chamam a atenção para o fato de que a imprecisão (ou mesmo o desconhecimento) dos autores da atualidade sobre os acontecimentos e as perspectivas do passado compromete o entendimento mais acurado das abordagens atuais justamente porque reproduzem distorções perigosas sobre o processo de formação do pensamento administrativo.

O presente ensaio se constitui a partir de três seções. $\mathrm{Na}$ primeira, fazemos uma breve análise dos aspectos epistemológicos que circundam a aproximação entre a perspectiva histórica e as ciências sociais, onde buscamos verificar os pontos que justificam a transição de uma tradição epistemológica dominante de natureza a-histórica para uma perspectiva analítica centrada na historicidade do fenômeno social. Na segunda seção, tecemos algumas considerações sobre a perspectiva histórica e o modo como vem sendo utilizada nos Estudos Organizacionais fora do Brasil. Na terceira seção, tratamos mais especificamente do objetivo do presente trabalho, ou seja, das contribuições da pesquisa histórica para os estudos organizacionais brasileiros, em que apresentamos pontos interessantes da literatura historiográfica que podem ajudar na compreensão da realidade organizacional e administrativa do país. Em nossas considerações finais, apresentamos alguns temas para uma agenda de pesquisa histórica sobre organizações e administração no Brasil.

\section{CONSIDERAÇÕES EPISTEMOLÓGICAS}

Nossa proposição de que a pesquisa histórica é algo importante para o avanço do conhecimento no campo dos estudos organizacionais se sustenta na reflexão sobre o desenvolvimento epistemológico nesta área, onde, a partir da contradição de certos elementos da perspectiva acadêmica dominante, verifica-se recentemente um movimento em favor de uma mudança de postura no meio que coloca a análise histórica em destaque (ÜSDIKEN e KIESER, 2004). Apresentamos a seguir os principais aspectos desse raciocínio.

\section{A natureza a-histórica do funcionalismo sociológico}

Tendo sido a abordagem funcionalista da sociologia o berço acadêmico da área de Estudos Organizacionais (BURRELL e MORGAN, 1979), não se pode negar que, apesar do crescente número de perspectivas alternativas dentro do campo, as bases epistemológicas do funcionalismo ainda predominam na pesquisa sobre organizações (BERTERO, 2005). E uma das premissas do funcionalismo sociológico é a tendência ao exame estático dos fenômenos sociais. Em razão disso, certos 
autores consideram a vertente funcionalista uma perspectiva a-histórica de pesquisa organizacional (BOOTH e ROWLINSON, 2006; ÜSDIKEN e KIESER, 2004; KIESER, 1994; ZALD, 1996).

O funcionalismo sociológico nasce sob influência direta das concepções apresentadas pelos autores do positivismo clássico, em especial Comte, Saint-Simon e Spencer. Sustenta-se enquanto abordagem científica a partir do modelo de ciência natural, tendo por referência principal a biologia. Desta, herdou termos e premissas, sendo duas das mais importantes a noção darwiniana de evolução e o sistema morfológico de análise das estruturas biológicas (BURRELL e MORGAN, 1979; GIDDENS, 1998). Assim, o interesse pela 'função' dos elementos que compõem o todo social representa uma analogia direta por parte dos funcionalistas das ciências sociais às estruturas biológicas. Para os críticos, esse aspecto conceitual-metodológico do funcionalismo indica acima de tudo uma tendência à análise das instituições sociais como estruturas estáticas, o que representa uma contradição à própria concepção evolucionista dessa abordagem (BURRELL e MORGAN, 1979). A premissa positivista de que a ciência deve se ater ao escrutínio das leis universais que regem os fenômenos observáveis se manifesta no funcionalismo sociológico por meio da preocupação em se revelarem os aspectos universais dos fenômenos sociais (GIDDENS, 1998; KIESER, 1994), menosprezando o conjunto de fatores que se modificam ao longo do tempo e em diferentes sociedades, fato esse significativamente mais evidente (BARRETT e SRIVASTVAL, 1991).

Para o campo de pesquisa organizacional, o reflexo dessa orientação acadêmica dominante foi um volume enorme de estudos empíricos formatados para a testificação de hipóteses e correlações causais que buscavam revelar o caráter universal da organização formal, ou seja, a crença de que esse tipo de organização humana apresenta características fundamentais independentes do contexto histórico. Como afirmam Barrett e Srivastval (1991, p. 234, tradução nossa), "esses esforços geraram uma imagem confusa da natureza progressiva da vida organizacional", já que contribuíram para que se estabelecesse a concepção das organizações enquanto estruturas estáticas. Todavia, se for considerada a necessidade de a ciência social compreender a vida humana a partir do relativismo imposto pelo contexto histórico-cultural (KIESER, 1994), a perspectiva dominante de pesquisa organizacional se apresenta como uma vertente acadêmica limitada e ingênua. A esse respeito, Zald (1996) lembra que o - 'universalismo' - a concepção do fenômeno organizacional contemporâneo como sendo típico de qualquer organização ao longo da história - e o 'presentismo' - o tratamento descontextualizado dos fenômenos organizacionais - correspondem a traços marcantes do ensino gerencial empreendido nas escolas de Administração, e essa condição compromete a capacidade analítica dos gestores, um problema que vem sendo observado também por outros autores (BEDEIAN, 2004; JACQUES, 2006).

A superação desse viés funcionalista de análise organizacional começou no momento em que abordagens $\mathrm{e}$ perspectivas alternativas sobre a realidade social surgiram no campo. Representadas analiticamente por Burrell e Morgan (1979) dentro de paradigmas alternativos ao funcionalista, essas diferentes vertentes se fundamentam a partir de pressupostos ontológicos, epistemológicos e metodológicos diversos daqueles associados ao pensamento do positivismo oitocentista. Um desses pressupostos é a natureza histórica das instituições sociais, aspecto tão relevante para o campo que marcou uma significativa mudança de perspectiva no cenário da pesquisa social, denominado guinada histórica (historical turn) em ciências sociais (BURKE, 2005; TUCHMAN, 1994; BARRETT e SRIVASTVAL, 1991; CLARK E ROWLINSON, 2004).

\section{A guinada histórica em ciências sociais}

A guinada histórica nas ciências sociais pode ser observada a partir de dois aspectos. Primeiro, sob a ótica do relativismo histórico-cultural que se estabeleceu por meio das correntes subjetivistas que despontaram em meados do século XX, tais como o interacionismo simbólico, a etnometodologia e a fenomenologia (BURRELL e MORGAN, 1979). O pressuposto básico desse relativismo é que diferentes culturas em diferentes momentos históricos representam diferentes significados e visões de mundo, tornando imprescindível ao pesquisador social reconhecer a posição de destaque da história na explicação dos fenômenos sociais (BARRETT e SRIVASTVAL, 1991). O segundo aspecto corresponde à consequente aproximação entre historiadores e cientistas sociais dada por essa superação do universalismo positivista, onde, para operacionalizar pesquisas fundamentadas em perspectivas epistemológicas e ontológicas mais refinadas, era necessário - por parte dos cientistas sociais - o uso de dados históricos na teorização sociológica e - por parte dos historiadores - o uso de teorias e conceitos sociológicos para uma análise histórica mais acurada (TUCHMAN, 1994; BURKE, 2005). Apesar dessa aproximação entre as disciplinas 'história' e 'sociologia/antropologia' ser algo conturbado (tendo em conta especialmente os interesses referentes à delimitação do campo de atuação do historiador e do cientista social [BURKE, 
2005]), ela representou uma transformação significativa em ambos os campos acadêmicos: para o cientista social, determinou a certeza de que "qualquer fenômeno social precisa ser entendido em seu contexto histórico" (TUCHMAN, 1994, p. 306, tradução nossa); para o historiador, representou o nascimento de uma 'história nova', centrada na busca de apreensão do passado em sua totalidade, na abordagem do fenômeno pela análise minuciosa dos fatos e significados e não apenas pela descrição seletiva dos acontecimentos (LÊ GOFF, 1998).

Pelo fato de a ideia de 'guinada histórica' estar vinculada ao grande processo de renovação epistemológica e metodológica que acometeu as ciências sociais em meados do século XX, é correto considerar esse movimento na mesma medida que as crescentes preocupações com a subjetividade, com o discurso e com a práxis nas ciências sociais. Nesse sentido, busca-se, nesse movimento de transformação, "uma abordagem diferente para a história" que permita "uma guinada para debates historiográficos e teorias históricas de interpretação, o reconhecimento da inerente ambiguidade do termo "história" (CLARK e ROWLINSON, 2004, p. 331, tradução nossa). Nesse raciocínio, além de uma preocupação aguda e direta com a pesquisa histórica na atividade do cientista social, a guinada histórica alude à busca de novos olhares sobre a história, que estejam comprometidos com as outras conquistas epistemológicas que desnudaram a fragilidade do ponto de vista positivista de análise e teorização. É assim que autores como Michel Foucault, Hayden White, Paul Ricour, Norbert Elias e outros se destacam como importantes referências teórico-metodológicas para os cientistas sociais contemporâneos (BOOTH e ROWLINSON, 2006; TUCHMAN, 1994).

Este último aspecto é particularmente relevante para a compreensão do papel que teve o movimento da guinada histórica nos Estudos Organizacionais. Mesmo reconhecendo que o funcionalismo dedicou certa atenção à história, ele o fez sob a concepção evolucionista, que foi metaforicamente incorporada por ocasião da forte influência da biologia (GIDDENS, 1998; BURRELL e MORGAN, 1979). Isso fez com que o funcionalismo sociológico observasse a história como um processo progressista, em que as estruturas sociais dos momentos históricos recentes se caracterizam como sendo mais complexas e sofisticadas em relação as estruturas do passado, dando a impressão de superioridade. É por esse motivo que as instituições características da modernidade (como por exemplo, as organizações formais) são erroneamente consideradas formas historicamente privilegiadas e, consequentemente, são objetivadas pelo cientista social funcionalista como modelo universal (GIDDENS, 1998). Em relação a esse problema, a guinada histórica em ciências sociais representa uma importante conquista. A partir de um novo olhar sobre a história, as ciências sociais reconhecem seus limites, admitindo seu papel ativo na formação de uma narrativa histórica específica (TUCHMAN, 1994). É por isso que as pesquisas devidamente fundamentadas na análise histórica permitem a reconstrução do conhecimento sobre o fenômeno administrativo e organizacional (JACQUES, 2006; CLARK e ROWLINSON, 2004; ZALD, 1996; KIESER, 1994).

\section{A PESQUISA HISTÓRICA NOS ESTUDOS ORGANIZACIONAIS}

Como mencionado acima, os Estudos Organizacionais participaram do movimento de guinada histórica em ciências sociais na medida em que este campo incorporou em seu quadro teórico de referência novas epistemologias historicamente orientadas (CLARK e ROWLINSON, 2004; BURRELL e MORGAN, 1979). Apesar de, neste específico campo acadêmico, não se observar uma expressiva articulação em torno da maior adoção da perspectiva histórica, percebe-se que esse intento vem ganhando força a partir dos esforços de certos pesquisadores, especialmente nos Estados Unidos - que já conta com uma divisão de Management History em sua academia há muitos anos - e na Europa, onde a temática é explorada em novos periódicos, tais como o Management and Organizational History, editado pela Sage a partir de 2006. Todavia, algumas considerações sobre os limites desses esforços para inserir a perspectiva histórica nos Estudos Organizacionais devem ser feitas. Primeiramente, devemos salientar que o interesse pela história na pesquisa organizacional se constitui a partir de múltiplas perspectivas epistemológicas, fato esse que leva a certa fragmentação e heterogeneidade na adoção da análise histórica no campo (ÜSDIKEN e KIESER, 2004; CLARK e ROWLINSON, 2004). Assim, dentro do grupo de pesquisas organizacionais historicamente informadas, temse o desenvolvimento de perspectivas de forte traço objetivista, tais como os estudos sobre história corporativa ou de negócios e as abordagens da análise de estratégias (CHANDLER, 1962; MINTZBERG e WATERS, 1982), mas também se encontram abordagens de cunho subjetivista, como, por exemplo, os estudos sobre discurso e poder inspirados em Foucault (ÜSDIKEN e KIESER, 2004; BOOTH e ROWLINSON, 2006), que têm na história um importante pressuposto teórico-analítico. 
No sentido de contribuir para o entendimento dessa diversidade, Üsdiken e Kieser (2004) propõem três diferentes posicionamentos comumente assumidos pelo pesquisador organizacional engajado na perspectiva histórica, o suplementarista, o integracionista e o reorientacionista. O suplementarista é o posicionamento que recorre à perspectiva histórica apenas no intuito de reforçar algum argumento teórico previamente construído. Nessa perspectiva, a história é apenas mais uma variável de análise empírica a ser considerada no corpus de pesquisa que, comparada a outros fatores, acaba por assumir uma importância menor. O problema de tal perspectiva é que considera de forma parcial ou distorcida a realidade histórica, já que recupera apenas os fatos históricos que sejam capazes de sustentar a teoria de base. Nesse sentido, para esta categoria de estudos, a história nunca é observada em sua totalidade, e a verdade dos fatos é aquela que já está predeterminada por explicações teóricas concebidas originalmente sem o crivo da análise histórica.

A perspectiva integracionista, por sua vez, corresponde ao enriquecimento da teorização organizacional por meio de uma acurada análise da realidade histórica, da integração entre as ciências sociais e a história almejada pelo já mencionado movimento da guinada histórica em ciências sociais. Apesar de os estudos de cunho integracionista considerarem as evidências históricas de forma mais séria (e menos enviesada) que a perspectiva suplementarista, eles o fazem sem necessariamente abandonar o interesse pela produção do conhecimento de natureza científica. Nesse aspecto, autores dessa vertente defendem que tanto a metodologia quanto a narrativa historiográfica são fundamentais para que o pesquisador das organizações possa ser bem-sucedido em seu intento, ou seja, a teorização sobre a realidade organizacional (ÜSDIKEN e KIESER, 2004).

A terceira perspectiva, a reorientacionista, considera de forma mais radical o papel da história no campo da pesquisa organizacional. Corresponde a uma redefinição epistemológica do campo a partir das premissas levantadas pelos historiadores e por certos filósofos, que põem sob suspeita o próprio conhecimento científico e seu papel enquanto legitimador de um saber social e historicamente determinado (BARRETT e SRIVASTVAL, 1991). Nesse sentido, os reorientacionistas propõem uma nova agenda de pesquisa para os estudos organizacionais, dada pela constatação do caráter a-histórico predominante no campo, que condiciona as concepções do pesquisador sobre a realidade organizacional e influencia seus interesses de pesquisa. A partir dessa vertente é que emergem estudos organizacionais 'alternativos' ao mainstream, tais como os estudos de gênero da perspectiva feminista (BOOTH e ROWLINSON, 2006) e outros estudos de cunho crítico (CLARK e ROWLINSON, 2004).

Outra maneira de se observar como as pesquisas organizacionais devem ser historicamente orientadas é por meio da cada vez mais intensa preocupação dos pesquisadores de organizações com a cultura. Nesse ponto, a aproximação entre a perspectiva histórica e a perspectiva cultural se explica especialmente pelo fato de que "diferenças entre organizações em diferentes culturas somente podem ser explicadas completamente se a dimensão histórica for incluída na comparação" (KIESER, 1994, p. 609, tradução nossa). Realmente, a relação imbricada entre a pesquisa histórica e o estudo da cultura se estabelece no momento em que a antropologia se constitui como campo acadêmico, elevando a antiga etnologia para o entendimento de culturas de sociedades arcaicas. Nesse momento, a antropologia se estabelece como ciência da cultura no sentido de que procura o entendimento da formação histórica de seu objeto, especialmente sob a influência do estruturalismo, representação analítica que foi decisiva para o surgimento da noção de 'tempo longo' (LE GOFF, 1998). Por outro lado, devemos considerar que o entendimento recente sobre a cultura tem sido uma das mais importantes contribuições para a chamada história social (LE GOFF, 1998; TUCHMAN, 1994).

Neste específico ponto, a pesquisa histórica se apresenta como uma opção para o campo de Estudos Organizacionais na medida em que a realidade organizacional é constituída sob forte influência do contexto nacional onde as organizações estão instaladas, o que aponta para a necessidade do entendimento da construção histórica dessas referências culturais nacionais. Nesse sentido, é necessário lembrar que a própria história organizacional e gerencial não se verifica sem a consideração da natureza multifacetada da cultura, que se estabelece enquanto rede de significações a partir de diferentes esferas de análise social (indivíduos, grupos, organizações e nações) e de todo o conjunto de fatores de manifestação social (simbólicos, econômicos, políticos, tecnológicos, etc.).

Sob o ponto de vista metodológico, é preciso considerar que a pesquisa histórica em estudos organizacionais está potencialmente atrelada a princípios de uma historiografia renovada. Isso significa dizer que, da mesma forma que os historiadores vinculados à nova história, esses esforços procuram explorar fontes historiográficas alternativas, mais adequadas às novas referências epistemológicas de cunho subjetivista, tais como a história oral e registros não oficiais, como cartas pessoais e jornais de época. Essa expansão das fontes historiográficas para além do acervo documental oficial permite que se escrutine melhor o con- 
texto cotidiano do passado. Tendo em conta que, para a Administração moderna, a história organizacional oficial é aquela contada pelos documentos e outros materiais de acervo da memória oficial, o cotidiano é explorado por fontes históricas alternativas, tais como acervos de sindicatos ou de familiares de trabalhadores, ou as sessões de jornais de época voltadas para populares (LOBO, 1997).

Outra interessante iniciativa que contribui para a construção de uma abordagem histórica em estudos sociais é o crescente interesse dos pesquisadores da área pela história da vida econômica e social cotidiana. Esses esforços têm sido empreendidos a partir da aproximação entre a atividade historiográfica com outros campos de pesquisa social, tais como a etnografia, a demografia e a análise macroeconômica (LE GOFF, 1998). Nessa trajetória, surgem campos interdisciplinares específicos, como a sociologia histórica, a antropologia histórica, a história cultural e a história econômica, todos representando disciplinas que, apesar das diferenças, procuram conciliar o entendimento do aspecto social com a compreensão da história. No campo dos Estudos Organizacionais, destacam-se as recentes contribuições da história de negócios, da história de gestão e da história corporativa (BOOTH e ROWLINSON, 2006).

Outra abordagem em Estudos Organizacionais com potencial para a pesquisa histórica é a teoria neoinstitucional. Tendo sido originada na Economia e na Sociologia, a teoria institucional nos Estudos Organizacionais vem aumentando seu número de adeptos no campo devido ao fato de que, em suas versões mais recentes, essa perspectiva acadêmica incorpora em seu quadro de referência teorias sociais que exigem uma devida vinculação histórica para a análise do aspecto social, tais como a teoria da estruturação de Giddens, que requer a avaliação do contexto histórico na medida em que pretende avaliar as práticas sociais em sua dinâmica recursiva com a ação humana dentro de contextos espaçotemporais específicos. Assim, a provável contribuição dos estudos neoinstitucionalistas reside no seu potencial em revelar a historicidade dos fenômenos organizacionais pela análise dos processos de institucionalização mais amplos que a eles estão vinculados. Todavia, para tal intento, é necessário ainda que os pesquisadores dessa perspectiva assumam a perspectiva histórica seriamente, algo que ainda não se evidencia nos estudos neoinstitucionalistas teórico-empíricos. Por exemplo, Machado-da-Silva é um pesquisador institucionalista dos mais profícuos na aproximação entre a história social e a análise organizacional, tendo até incorporado diretamente a análise historiográfica em seus estudos sobre organizações brasileiras (MACHADO-DA-SILVA e NOGUEIRA, 2001).
É preciso considerar ainda que, nos poucos esforços pela história na pesquisa organizacional, existem problemas no que diz respeito ao rigor metodológico. Por exemplo, um problema relativamente simples - porém grave - que nem sempre é observado pelo pesquisador organizacional no empreendimento historiográfico é a escolha das fontes de dados, que quase sempre são poucas e duvidosas. Nesse sentido, Jacques (2006) chama a atenção para os principais equívocos no campo de estudos organizacionais na aplicação da análise histórica, dentre eles, a confusão entre estudos longitudinais e estudos históricos, o diletantismo em relação à prática historiográfica, a fragilidade no uso metafórico da história de guerra em análise organizacional e o anacronismo presente em certas referências à história da humanidade. Paradoxalmente, tais problemas da análise histórica empreendida na Administração configuram um aforismo anti-histórico, já que isso "reduz a história a um fenômeno putativamente atemporal e ilustrativo" (JACQUES, 2006 , p. 41 , tradução nossa). Isso significa dizer que, na perspectiva desse autor, a história geralmente assume um papel meramente figurativo na literatura de Administração, de tal forma que sua consideração não cause nenhuma alteração na perspectiva organizacional funcionalista (que, conforme já foi observado, consiste em uma perspectiva universalista e a-histórica sobre esse fenômeno). Consequentemente, a constituição desse discurso histórico da realidade organizacional é frágil e descompromissada com a acurada validação das fontes historiográficas que descrevem os fatos e eventos históricos, bem como as análises preestabelecidas destes.

Assim sendo, Jacques (2006) e outros autores (KIESER, 1994; BOOTH e ROWLINSON, 2006; ZALD, 1996; ÜSDIKEN e KIESER, 2004; CLARK e ROWLINSON, 2004) defendem que o uso da história nos estudos organizacionais seja feito justamente tendo em vista a reformulação teórica do fenômeno organizacional. De acordo com esse entendimento, a investigação histórica do fenômeno organizacional e da atividade gerencial deve "conectar-se com questões atuais no sentido de que podem levar a uma perspectiva diferente [das que vigoram] sobre tais questões" (JACQUES, 2006, p. 43, tradução nossa), ou seja, devem ser capazes de questionar o entendimento vigente da realidade organizacional contemporânea pela reconstrução dessa realidade feita com o minucioso escrutínio de sua trajetória histórica. Essa potencial reconstrução teórica promovida pela investigação histórica pode ser apreciada pelas considerações que se seguem sobre o caso particular dos Estudos Organizacionais brasileiros. 


\section{ALGUMAS CONTRIBUIÇÕES DA PESQUISA HISTÓRICA AOS ESTUDOS ORGANIZACIONAIS BRASILEIROS}

A partir de nossas considerações prévias, podemos supor que a Administração e as organizações no Brasil somente serão satisfatoriamente compreendidas no momento em que se buscar um entendimento destas a partir de suas referências histórico-culturais específicas. Apesar de óbvio, esse pensamento não reflete os esforços da academia brasileira, que, ao se sujeitar aos modelos importados e teorizações de largo escopo constituídas em outros contextos - especialmente, os Estados Unidos (CALDAS e WOOD JR, 1999; WOOD JR. e CALDAS, 2002; BERTERO, 2006; VIZEU, 2008) -, omite a história local como elemento fundamental na construção da realidade administrativa e organizacional brasileira. Isso transparece de forma evidente ao se observar a produção acadêmica, onde se verificam muito poucos trabalhos que constituem pesquisas históricas formatadas com o objetivo de reconstrução teórica (configurando as perspectivas 'integracionista' e 'reorientacionista'). Além disso, vários estudos revisionais da produção acadêmica brasileira confirmam a dificuldade de se produzir um conhecimento genuinamente local, sustentado por teorias contextualizadas em nossa própria realidade (CALDAS e WOOD JR, 1999; BERTERO, 2005). Diante desse quadro é que vemos na pesquisa histórica uma abordagem de investigação acadêmica proveitosa para o campo dos Estudos Organizacionais brasileiros.

De acordo com Miceli (2001), a historiografia social nacional caracteriza-se pelo seu compromisso com os ditames do movimento da história nova, especialmente a profícua produção historiográfica do início do século $\mathrm{XX}$, que refletiu um maior interesse analítico e multidisciplinar capaz de revelar facetas da identidade brasileira. Assim, a historiografia do Brasil torna-se 'social' especialmente a partir da publicação de três importantes textos na década de 1930: Casa-grande E senzala, de Gilberto Freyre, Raizes do Brasil, de Sergio Buarque de Holanda, e Formação do Brasil contemporâneo, de Caio Prado Júnior, três textos que representam a ruptura no Brasil com uma história de conveniências políticas (denominada pelos historiadores contemporâneos discurso de história oficial) e limitações epistemológicas. Desses autores (hoje considerados) clássicos, surge uma tradição historiográfica diversificada, interessada nas questões do homem comum, fundamentada em métodos e fontes alternativas de coleta e análise de dados históricos, nas mentalidades de épocas remotas, mas principalmente na perspectiva totalizante do passado, onde a cultura popular, o cotidiano dos margina- lizados (por exemplo, escravos e mulheres), mas também a vida das elites (corte e senhores de engenho), a política econômica e o cenário mundial se inter-relacionam em um emaranhado complexo que se constitui como contexto histórico brasileiro.

Outro segmento que também se configura como um campo de estudo profícuo rumo ao entendimento da realidade brasileira é a história econômica. Nesse campo, além da produção de pesquisadores nativos, existe uma significativa produção estrangeira, especialmente até meados do século XX, quando o interesse pelo Brasil fervilhava no mundo todo. Autores estrangeiros denominados 'brasilianistas' se debruçaram sobre a análise histórica do desenvolvimento econômico nacional, especialmente no intuito de melhor compreender os elementos históricosociais importantes na configuração de uma realidade econômica tão díspar de outros países de iguais condições e características. Dentro desse seguimento, destacam-se trabalhos como os de Werner Baer, Stanley Stein e Thomas Skidmore, e mesmo de brasileiros nativos, como Celso Furtado e Wilson Suzigan. Além de um olhar diferenciado sobre a estrutura econômica do passado, os estudos de história econômica também se preocupam com a dimensão sociocultural na configuração da economia (STEIN, 1960). Nesse sentido, um estudo interessante foi a análise feita por Luz (1975) sobre o processo de industrialização no Brasil. Além dos aspectos econômicos e políticos que influenciaram o surgimento e desenvolvimento da industrialização no Brasil do século XIX, a autora salienta o quadro ideológico que sustentou esse cenário conturbado, de idas e vindas, de momentos de grande avanço seguidos de retrocessos, naquilo que ela denomina 'luta' pela industrialização.

Para exemplificar a maneira como a ponte com a historiografia social e econômica pode ser proveitosa para os Estudos Organizacionais brasileiros, apresentamos alguns pontos tratados na literatura, assinalando suas implicações diretas para a compreensão da realidade organizacional e administrativa. Para reforçar seu caráter complementar, apresentamos esses temas em sequência.

\section{A herança rural e sua influência na atividade industrial no início do século XX}

Boa parte da historiografia social e econômica brasileira dá conta da formação institucional do país e da herança rural do período colonial. Pela denominação 'América portuguesa', os historiadores pretendem sinalizar que o período colonial do país refletiu uma longa trajetória de construção das instituições de base do país, seja na esfera política, seja no interior das relações sociais mais estreitas 
(MICELI, 2001). Nesse sentido, um importante aspecto apontado pelos historiadores é a herança rural do período colonial (HOLANDA, 2001), que se fez sentir decisivamente na construção de um projeto de modernização das instituições do país ao longo do século XIX. Assim, de forma singular, nosso projeto de modernização - que, entre outras coisas, significou a racionalização da Administração nas esferas pública e privada - foi marcado pelo vanguardismo em relação a importantes países do hemisfério norte - basta lembrar que a industrialização no país foi ensaiada por dom João na sua chegada ao país, em 1808, um período anterior ao dos esforços nos Estados Unidos (LUZ, 1975), mas também foi minada pelo interesse de uma aristocracia rural que, devido a sua força política e a outro conjunto de fatores favoráveis (como, por exemplo, o apoio político dos ingleses [GRAHAM, 1973]), impetrou diversas vezes a bancarrota do projeto de modernização. Com isso, as condições de sustentação de uma sociedade racionalmente organizada e de uma economia industrializada, condições fundamentais para o estabelecimento do management moderno (VIZEU, 2008), foram anacronicamente constituídas, em um processo que se arrasta desde o início do século XX, e que somente em meados do século seguinte poderá ser considerado finalizado (BERTERO, 2006).

A herança rural do período colonial também é tratada em estudos da história do cotidiano. O célebre ensaio de Freyre (2003) sobre a vida cotidiana nas grandes propriedades rurais revela matizes de nossa tessitura social - especialmente quanto aos aspectos patrimonialistas das relações sociais nesses grandes empreendimentos econômicos do Brasil oitocentista. Nesse sentido, o caráter patriarcal e personalista da grande propriedade rural remonta a aspectos institucionalizados na sociedade tradicional brasileira, e sua presença vem sendo apontada pelos estudos sobre a gestão e organização brasileiras (por exemplo, vários textos da coletânea de Caldas e Motta [1999] sobre a cultura organizacional e a cultura brasileira).

Finalmente, outro aspecto do processo de modernização do Brasil foi a baixa predisposição às relações de trabalho que sustentam a empresa industrial, já que, durante o ímpeto da atividade industrial nas primeiras décadas do século XX, o Brasil mal acabara de romper com o sistema escravocrata. Assim, na aurora da industrialização brasileira, além do problema da mão de obra despreparada para a rotina do trabalho industrial (GRAHAM, 1973), a elite industrialista herdou da escravidão oitocentista uma mentalidade pouco afeita aos imperativos das relações de trabalho modernas (DEAN, 2001), tais como a sindicalização, aos direitos trabalhistas e mesmo ao fato de a recompensa ao trabalho ser essencialmente pecuniária. Finalmente, a conturbada ordem institucional do período colonial - caracterizada na esfera social e política pelo patrimonialismo (um termo que indica prática da apropriação do público pelo privado [FAORO, 2001]) influenciou decisivamente a Administração no Brasil, pois se fez presente no seio da ordem social e política do país durante a introdução da doutrina do management no início do século XX (VIZEU, 2008; MARTINS, 1999).

\section{0 desenvolvimento econômico e político do início do século XX e seu impacto na adoção de práticas modernas de Administração}

Tanto a história política quanto a econômica das primeiras fases do Brasil republicano revelam aspectos da realidade social que são fundamentais para a compreensão das práticas modernas de gestão em nosso país. Primeiramente, existe uma expressiva literatura historiográfica que tenta explicar por que o processo de industrialização no Brasil ocorre tardiamente e concentrado na região de São Paulo (RATNER, 1972); por sua vez, esses estudos revelam questões que destacam a importância do desenvolvimento político e econômico do país daquele período na recepção das modernas doutrinas de Administração por parte da elite industrial brasileira (VIZEU, 2008). Nesse sentido, aspectos como a influência da economia cafeeira de 1900 enquanto formadora de condições estruturais para o ímpeto industrial nas primeiras décadas daquele século (DEAN, 2001) sugerem a formação de uma mentalidade empresarial nem sempre propícia para receber os fundamentos racionalizadores da doutrina do management norte-americano (VIZEU, 2008). Além de ser um importante aspecto norteador da compreensão da história da Administração moderna em nosso país, a nossa formação política e econômica recente também informa nossa própria identidade gerencial, tendo em conta os estudos que apontam para a permanência de características de uma mentalidade empresarial refratária aos pressupostos da moderna gestão, como, por exemplo, aquela que aceita com dificuldades a separação racional entre o poder de propriedade e o poder gerencial ou a dificuldade em assimilar a formação profissionalizante e técnica nos cargos mais altos das empresas brasileiras, questões essas identificadas por estudos sobre a administração das empresas brasileiras de meados do século XX (CARDOSO, 1972; BRESSER-PEREIRA, 1974).

A história política de início de século também é de grande relevância para a compreensão da Administração moderna no Brasil, tendo em conta o papel de destaque do Estado na introdução e disseminação de ideologias 
administrativas modernas no país. Nesse ponto, os esforços do governo Vargas na introdução de princípios de administração científica e racional são lembrados com destaque por alguns autores. A formação do Departamento Administrativo do Serviço Público (DASP) e a criação da Fundação Getulio Vargas são lembradas como duas medidas decisivas para o estabelecimento de uma prática gerencial moderna no Brasil, seja na esfera pública (WAHRLICH, 1983) ou privada (BERTERO, 2006). O DASP, em particular, foi uma medida importante para a consolidação da modernização da Administração pública, já que foi um órgão cujo objetivo fundamental era a profissionalização do funcionalismo estatal, sob os auspícios da racionalidade burocrática. Todavia, apesar de esse processo envolver princípios que representavam uma significativa ruptura com a tradição política colonial/imperial, Martins (1999) observa que o desenvolvimento da estrutura burocrática apenas salientou o ethos patrimonialista, na medida em que contribuiu para a criação de duas esferas separadas de poder, a técnica, representada pela estrutura burocrática (modernização administrativa), e a política, ideologicamente justificada pelo advento da democracia representativa (modernização política). A despeito dos esforços em prol da racionalização da administração pública, permanecia a orientação patrimonialista herdada do período colonial, gerando aquilo que Martins (1999, p. 181) denominou modernização dissociativa, "onde a construção burocrática é tendencialmente obstaculizada pela política". Esse panorama contraditório da Administração pública brasileira retrata a sua natureza ímpar, de difícil compreensão por parte dos estrangeiros, porém, somente acessível a partir da reconstrução histórica.

\section{CONSIDERAÇÕES FINAIS}

Olhar para nosso passado é algo necessário para que a academia brasileira avance no entendimento da identidade organizacional e gerencial nacional. Todavia, não somente devemos olhar o passado recente, julgando que a história da Administração no Brasil se fez a partir do estabelecimento da industrialização e do ensino da Administração no país, ou na fundação das grandes corporações e grupos empresariais nacionais: devemos buscar no Brasil mais distante as bases de uma possível identidade gerencial e organizacional brasileiras. Assim, entender a gestão brasileira por completo significa entender o Brasil em sua totalidade social, cultural, econômica e política, tarefa essa somente possível por meio do olhar histórico.

Isso posto, é possível considerar alguns temas que ilustrem futuras pesquisas históricas nos Estudos Organizacionais brasileiros. Estes representam uma transposição para o caso brasileiro dos argumentos levantados por autores estrangeiros que vêm se dedicando à disseminação da abordagem histórica na pesquisa organizacional e de Administração, como, por exemplo, Booth e Rowlinson (2006), Jacques (2006), Clark e Rowlinson (2004), Üsdiken e Kieser (2004), Kieser (1994) e Zald (1996). Tendo em conta o caráter do presente ensaio, não tivemos a intenção de ser exaustivos na apreciação do assunto, tratando-se antes de um esforço preliminar que aponte para um debate futuro sobre o desenvolvimento sistemático da pesquisa histórica nesse campo. A intenção de apresentar esses temas é a de apresentar os contornos de uma possível agenda de pesquisa, onde os temas representam possibilidades a serem exploradas. Eles devem ser considerados a partir do nosso argumento de que a pesquisa histórica pode contribuir para a teorização da realidade organizacional brasileira. Assim, tais temas poderão ser mais aprofundados (ou mesmo questionados) em artigos futuros.

\section{Estudos sobre a história do pensamento administrativo brasileiro}

No exterior, um tipo de estudo histórico que vem se desenvolvendo com grande força dentro da Administração se relaciona com a história do pensamento administrativo moderno. Tendo em conta a peculiar maneira como se estabelecem as abordagens de gestão em nosso país, esse tipo de análise pode ser de grande valia para um entendimento mais acurado do pensamento administrativo brasileiro, além de também ser algo proveitoso para o entendimento de outros contextos nacionais, considerando que os estudos históricos provêem uma interessante possibilidade de análise comparativa (KIESER, 1994; BENDIX, 1974). Nesse sentido, a partir da perspectiva de importação de metodologias gerenciais, um bom exemplo de como a adoção de uma perspectiva histórica na pesquisa em Administração no Brasil pode ser frutífera tem sido a preocupação de certos autores em revelar as condições nas quais se estabeleceu o ensino formal de Administração no país (BERTERO, 2006). Por fim, estudos historiográficos sobre personagens importantes do pensamento administrativo brasileiro, tais como Roberto Simonsen (que exerceu significativa influência na introdução do taylorismo no país [VIZEU, 2008]) e outros mais contemporâneos, como Guerreiro Ramos e Maurício Tragtemberg, podem revelar aspectos da mentalidade de uma época que foram determinantes para o desenvolvimento de certos princípios e práticas administrativas. 


\section{Estudos históricos sobre ideologias e discursos associados a práticas organizacionais}

A ideologia tem sido uma questão significativa nas pesquisas organizacionais historicamente orientadas. Isso porque a análise organizacional é comumente marcada pela conotação ideológica (KIESER, 1994). Assim, estudos sobre as práticas organizacionais brasileiras devem ter em conta o contexto ideológico que suportou a adoção destas, porque um determinado modelo ou ferramenta gerencial teve maior impacto que outros, etc. Da mesma forma, a análise do passado permite melhor observar o caráter ideológico das práticas e concepções prescritas no presente. Nessa linha de pesquisa, estudos organizacionais baseados na perspectiva de Foucault - tão comuns na área de Estudos Organizacionais - podem prover significativa contribuição. Outro interessante exemplo de estudo histórico sobre ideologias é apresentado por Bendix (1974), mas com um sentido diverso da conotação crítica do discurso. Esse autor procurou entender as diferenças entre as relações de autoridade da gestão industrial em diferentes países, a partir das diferenças dos contextos ideológicos que historicamente suportaram tais sistemas de autoridade, e demonstrar distintos contornos de práticas gerenciais institucionalizadas em nossa era. No Brasil, um interessante estudo nessa linha é o ensaio de Pena (1985) sobre a introdução de ideologias gerenciais no país.

\section{Estudos sobre história corporativa e de negócios no Brasil}

No exterior, a história de negócios e corporativa representa uma importante fonte para os Estudos Organizacionais historicamente orientados (BOOTH e ROWLINSON, 2006). No Brasil, as fontes são restritas aos poucos periódicos especializados nessa linha e aos eventuais trabalhos publicados em canais acadêmicos mais genéricos (geralmente associados à história geral ou história econômica). Assim, uma forma interessante para aproveitar o desenvolvimento da história corporativa e de negócios é recorrer às iniciativas de grandes empresas no Brasil que desejam manter acervos e museus sobre sua própria história. O cuidado que se deve ter em tais esforços é o viés na formatação desses dados, um problema comumente associado à história de negócios, tendo em conta que estes são selecionados e narrados pelas próprias corporações, quase sempre interessadas em 'escrever' a história que lhes convém, omitindo certos fatos e exaltando outros (LOBO, 1997).

Por fim, devemos considerar que a pesquisa histórica deve ser empreendida com o objetivo de tornar mais inteligível a realidade organizacional brasileira contempo- rânea. Nesse sentido, além de permitir uma observação mais acurada das peculiaridades das organizações brasileiras contemporâneas, a abordagem histórica pode ser um caminho para que os estudos organizacionais brasileiros vislumbrem sua identidade acadêmica.

\section{REFERÊNCIAS}

BARRETT, F. J; SRIVASTVAL, S. History as a mode of inquiry in organizational life: a role of human cosmogony. Human Relations, v. 44, n. 3, p 231-254, 1991

BEDEIAN, A. G. The gift of professional maturity. Academy of Management Learning and Education, v. 3, n. 1, p. 92-98, 2004

BENDIX, R. Work and authority in Industry. Berkeley: University California Press, 1974.

BERTERO, C. O. Estudos organizacionais em perspectiva. RAE-revista de administração de empresas, v. 45, n. 1, p. 92-93, 2005.

BERTERO, C. O. Ensino e pesquisa de administração. São Paulo: Thomson Learning, 2006

BOOTH, C; ROWLINSON, M. Management and organizational history: prospects. Management $\mathcal{E}$ Organizational History, v. 1, n. 1, p. 5-30, 2006

BRESSER-PEREIRA, L. C. Empresários e administradores no Brasil. São Paulo: Brasiliense, 1974.

BURRELL G; MORGAN, G. Sociological Paradigms and Organizational Analysis. London: Heinemann, 1979.

BURKE, P. History and Social Theory. 2. ed. New York: Cornell University Press, 2005.

CALDAS, M. P; MOTTA, F. C. P. (Orgs) Cultura organizacional e cultura brasileira. São Paulo: Atlas, 1999.

CALDAS, M. P; WOOD JR, T. Para inglês ver: importação de tecnologia gerencial no Brasil. In: CALDAS, M. P; WOOD JR, T. Transformação e realidade organizacional: uma perspectiva brasileira. São Paulo: Atlas, 1999, p. 27-44

CARDOSO, F. H. Empresário industrial e desenvolvimento econômico no Brasil. 2. ed. São Paulo: Difusão Europeia do Livro, 1972

CHANDLER, A. D. Strategy and Structure. Cambridge, MA: MIT Press, 1962

CLARK, P; ROWLINSON, M. The treatment of history in organization studies: towards an 'historic turn'? Business History, v. 46, n. 3, p. 331 $352,2004$. 


\section{FÁBIO VIZEU FERREIRA}

FAORO, R. Os donos do poder. 3. ed. São Paulo: Globo, 2001.

FREITAS, M. C. (Org) Historiografia brasileira em perspectiva. 4. ed. São Paulo: Contexto, 2001.

FREYRE, G. Casa-grande E senzala. 47. ed. rev. São Paulo: Global, 2003.

GIDDENS, A. Política, sociologia e teoria social. São Paulo: Unesp, 1998.

GRAHAM, R. Grã-Bretanha e o início da modernização no Brasil. São Paulo: Brasiliense, 1973.

HOLANDA, S. B. de. Raizes do Brasil. 26. ed. São Paulo: Companhia das Letras, 2001.

JACQUES, R. S. History, historiography and organization studies: the challenge and the potential. Management \& Organizational History, v. 1, n. 1, p. 31-49, 2006

KIESER, A. Why organization theory needs historical analyses. Organization Science, v. 5, p. 608-620, 1994.

LE GOFF, J. A história nova. In: A história nova. São Paulo: Martins Fontes, 1998. p. 25-64.

LOBO, E. L. História empresarial. In: CARDOSO, C. F; VAINFAS, R. (Orgs) Domínios da história: ensaios de teoria e metodologia. Rio de Janeiro: Campus, 1997. p. 217-239.

LUZ, N. V. A luta pela industrialização no Brasil. Rio de Janeiro: AlfaÔmega, 1975.

MACHADO-DA-SILVA, C. L; NOGUEIRA, E. E. da S. Identidade organizacional: um caso de manutenção, outro de mudança. Revista de Administração Contemporânea, v. 5, n. especial, p. 35-58, 2001.

MARTINS, H. A ética do patrimonialismo e a modernização da administração pública brasileira. In: CALDAS, M. P; MOTTA, F. C. P. (Orgs) Cultura organizacional e cultura brasileira. São Paulo: Atlas, 1999.
MICELI, P. Sobre a história, Braudel e os vaga-lumes. A Escola dos Annales e o Brasil (ou vice-versa). In: FREITAS, M. C. (Org) Historiografia brasileira em perspectiva. 4. ed. São Paulo: Contexto, 2001. p. 259-270.

MINTZBERG, H; WATERS, J. A. Tracking strategy in an entrepreneurial firm. Academy of Management Journal, v. 25, n. 3, p. 465-499, 1982.

PENA, M. V. J. A introdução de ideologias gerenciais no Brasil. RAE-revista de administração de empresas, v. 25, n. 3, p. 23-30, 1985.

STEIN, S. The historiography of Brazil 1808-1889. The Hispanic American Review, v. 40, n. 2, p. 234-278, May 1960.

TUCHMAN, G. Historical social science: methodologies, methods, and meanings. In: DENZIN, N; LINCOLN, Y. (Ed) Handbook of Qualitative Research. London: Sage, 1994. p. 306-323.

ÜSDIKEN, B; KIESER, A. Introduction: history in organization studies. Business History, v. 46, n. 3, p. 321-330, July 2004.

VIZEU, F. Management no Brasil em perspectiva histórica: o projeto do IDORT nas décadas de 1930 e 1940. 254 p. Tese de Doutorado em Administração, Escola de Administração de Empresas de São Paulo da Fundação Getulio Vargas, São Paulo, 2008.

WAHRLICH, B. M. de S. A reforma administrativa da era de Vargas. Rio de Janeiro: Fundação Getulio Vargas, 1983.

WOOD JR, T; CALDAS, M. P. Adopting imported managerial expertise in developing countries: the Brazilian experience. Academy of Management Executive, v. 16, p. 18-32, 2002

ZALD, M. N. More fragmentation: unfinished business in linking the social sciences and the humanities. Administrative Science Quarterly, v. 41 p. 251-261, 1996. 